\title{
MELMOTH, EL FANTASMA DE CHARLES R. MATURIN: REGRESO ESPECTRAL DE LA LITERATURA GRECOLATINA ${ }^{1}$
}

\author{
ANA GONZÁLEZ-Rivas FERNÁNDEZ \\ Universidad Complutense de Madrid \\ anagonfer27@telefonica.net
}

\section{RESUMEN}

A diferencia de la idea que se ha defendido tradicionalmente, la literatura gótica no sólo no es opuesta a la literatura grecolatina, sino que ésta puede llegar a desempeñar un papel central en la narrativa de terror que apareció en Inglaterra a finales del siglo XVIII. Ejemplo de ello es Melmoth, the Wanderer (1820), de Charles Robert Maturin, donde tiene especial relevancia el uso de la cita en latín y en griego. En este artículo se estudiará cómo los textos de tres autores clásicos (Plinio el Joven, Homero y Virgilio) configuran el marco para el «fantasma» moderno que presenta Maturin en su novela. Asimismo, se analizará la presencia de la carta de Plinio sobre fantasmas (Plin.Ep.7.27.1-11) como hipotexto de Melmoth, the Wanderer, en el que aparece explícitamente a través de una «doble cita». Se comprobará de esta forma que clásicos y góticos pueden estar unidos por un mismo interés en lo sobrenatural.

PALABRAS Clave: Literatura grecolatina, Literatura gótica inglesa, Intertextualidad, Cita, Fantasma.

${ }^{1}$ Este trabajo se inscribe en el Grupo UCM 930136 «Historiografía de la Literatura Grecolatina en España» y en el proyecto MEC HUM2007-60326/FILO «Historiografía de la Literatura Grecolatina en España: la Edad de Plata (1868-1936)», financiado por el Ministerio de Educación y Ciencia. Quisiera agradecer sus consejos al profesor Francisco García Jurado, que realizó una atenta supervisión de este artículo. 


\section{ABSTRACT}

Contrary to traditionally accepted ideas, Gothic literature is no simple opposite of Greco-Latin literature. Indeed it may be argued that the Classics play a central role in the narrative of terror that emerged in England at the end of the 18 ${ }^{\text {th }}$ century. A good example of this can be seen in Charles Robert Maturin's Melmoth, the Wanderer (1820), where the quotations from Latin and Greek texts are particularly relevant. In this article I shall analyse how the texts of three classical writers (Pliny the Younger, Homer and Virgil) provide the framework for the modern «ghost» that Maturin depicts in his novel, and examine the influence of Pliny's letter about ghosts (Plin.Ep.7.27.1-11) as an hypotext of Melmoth, the Wanderer, where it explicitly appears as a «double quotation». This shows that further links can be established between the Classical and the Gothic through their sharing of an interest in the supernatural.

KEY WoRDs: Greek-Latin literature, English Gothic literature, Intertextuality, Quotation, Ghost.

\section{INTRODUCCIÓN}

En muchos estudios sobre novela gótica se ha afirmado que este género es opuesto a la literatura clásica y a la estética grecolatina: «where the classical was well ordered, the Gothic was chaotic; where the classical was simple and pure, Gothic was ornate and convoluted; where the classics offered a world of clear rules and limits, Gothic represented excess and exaggeration, the product of a wild and uncivilized, a world that constantly tended to overflow cultural boundaries $»^{2}$, dicen Punter \& Byron, 2004:7; Sowerby, en otro estudio (Punter (ed.), 2006:15-16), dice que «through history the word "Gothic" has always been chiefly defined in contrasting juxtaposition to the Roman, and a constant factor in its various uses, perhaps the only constant factor, has continued to be its antithesis to the Roman or the classical, an antithesis that is wittily expressed by the sophisticated Touchstone when he finds himself among the simple rustics of the forest of Arden: "I am here with thee and thy goats as the most capricious poet, honest Ovid, was among the Goths"» ${ }^{3}$. Frente a estos planteamientos teóricos, Melmoth, the Wanderer, de Charles Robert Maturin, es el ejemplo de que la oposición entre lo clásico y lo gótico no sólo no se da de una forma tan tajante, sino que la literatura grecolatina puede llegar a desempeñar un papel central en este género romántico.

\footnotetext{
2 «Donde lo clásico estaba bien ordenado, lo gótico era caótico; donde lo clásico era simple y puro, lo gótico era adornado y retorcido; donde los clásicos ofrecían un mundo de normas y márgenes definidos, lo gótico representaba el exceso y la exageración, el producto de lo salvaje y lo incivilizado, un mundo que tiende constantemente a desbordarse de sus límites». La traducción es mía.

3 «A lo largo de la historia el término 'gótico' ha sido siempre definido principalmente por yuxtaposición y en contraste con lo romano, y un factor constante en sus diferentes usos (posiblemente el único factor constante) ha sido su antítesis con lo romano o con lo clásico, una antítesis que es ingeniosamente expresada por el sofisticado Touchstone, cuando, en medio de toscos aldeanos del bosque de Arden, dice 'Estoy aquí contigo y con tus cabras como el más caprichoso poeta, el honrado Ovidio, estaba entre los godos'». La traducción es mía.
} 
Charles Robert Maturin (Dublín, 1782-1824) fue un predicador protestante anglo-irlandés. Además de algunos dramas, publicó varias novelas, aunque no fueron muy exitosas. El triunfo definitivo le llegó en 1820 con Melmoth, the Wanderer, una obra con la que se culmina el primer ciclo de la novela gótica inglesa. Melmoth, the Wanderer trata sobre un hombre que, tentado por el deseo de poder y de inmortalidad, hace un pacto con el diablo para vivir 150 años más. En ese tiempo debe encontrar a alguien que quiera cambiarle el destino; de lo contrario, será arrastrado hacia el infierno ${ }^{4}$. La vida de Melmoth, el errabundo, la conocemos a través de las historias que oye o que lee un pariente suyo, John Melmoth, que trata de descubrir lo que esconde tan misterioso antepasado. Son en total cinco historias organizadas en estructura de cajas chinas (la historia de Stanton, la del español, la de los indios, la de la familia de Guzmán y la de los amantes) en las que se observa cómo Melmoth aprovecha los momentos de mayor desgracia para aproximarse a sus víctimas, esperando conseguir así que algún incauto, movido por la desesperación, acceda al intercambio. Esta novela, que recoge muchos de los tópicos que habían ido estableciendo autores como Matthew Gregory Lewis o Ann Radcliffe, marca el fin de un período y la consolidación de un género que no volverá a reaparecer con fuerza hasta finales del siglo XIX.

Mi objetivo en este artículo es exponer cómo se articula la literatura clásica en la novela de Maturin, donde tiene especial relevancia el uso de la cita en latín y en griego. Para ello partiré de los estudios de García Jurado (2000, 2002, 2006, 2008a, 2008b), que ya ha demostrado la importancia que tienen algunos autores clásicos, como Plinio y Virgilio, en la literatura de terror. Basándome en ellos, trataré de demostrar que la carta de Plinio el Joven sobre fantasmas (Plin.Ep.7.27.5-11) es uno de los textos literarios con los que Maturin construye su novela, explícita e implícitamente. Centraré el estudio principalmente en los capítulos III y XXIII de Melmoth, the Wanderer, unidos por la misma cita del texto latino. Veremos que el fantasma de Plinio «resucita» a su vez a otros dos fantasmas literarios también presentes en sendas citas de la novela: el fantasma de Héctor, que aparece en la Eneida de Virgilio, y el fantasma de Patroclo, que aparece en la Ilíada de Homero. La convergencia de estos tres fantasmas clásicos crea la base para el fantasma moderno de Maturin, cuya obra, además, es altamente erudita y está repleta de referencias al mundo grecolatino. Al final del artículo, habremos comprobado que Melmoth, the Wanderer es un destacado ejemplo de las relaciones entre la literatura clásica y la literatura gótica, y que éste es uno de los aspectos más relevantes de la obra. Se demostrará así que las dos literaturas, lejos de ser realmente opuestas, mantienen, en realidad, una relación de tensión, donde son dos fuerzas que chocan, pero que funcionan conjuntamente. En definitiva, se puede entender la literatura gótica como la primera relectura de la literatura grecolatina en clave no clasicista.

${ }^{4}$ Parte de la historia de Melmoth, the Wanderer está basada en el mito cristiano del judío errante. Según este mito, un judío insultó a Jesús durante la crucifixión. Éste le condenó a errar sin descanso por el mundo hasta la Parousía, esto es, hasta la segunda llegada de Cristo a la tierra. 


\section{LA CITA INICIAL. EsPeCtRos ClÁSICOS: El FANTASMA DE Plinio y los fANTASMAS ÉPICOS DE HOMERO Y VIRGILIO}

Todos los capítulos de Melmoth, the Wanderer, salvo el IX, están introducidos por una cita inicial de la literatura inglesa, francesa, italiana, española, griega o latina. Las citas tienen una relación más o menos explícita con el contenido del capítulo, y por tanto, son imprescindibles en el conjunto de la obra. Estudiaremos en este apartado el caso de una cita inicial de Plinio especialmente relevante en la novela de Maturin, así como otros dos textos, de Homero y de Virgilio, que están en estrecha relación con esta cita.

La cita que abre el capítulo III es la siguiente:

\section{Apparebat eidolon senex 5 PLINIO.}

Maturin no especifica qué Plinio es (el Viejo o el Joven), dándolo por supuesto o, quizá, jugando con el equívoco. Algunos lectores familiarizados con la literatura clásica posiblemente sean capaces de identificar la carta que Plinio el Joven envía a Sura (Plin.Ep.7.27.5-11). En ella, tratando de responder a una pregunta sobre la existencia de los fantasmas, Plinio cuenta, a modo de excurso, la historia de una casa encantada ${ }^{6}$. Según González (1999:44), éste es el primer relato de fantasmas con referencias a lo sobrenatural, lo que justifica, en parte, el interés que Maturin pudo sentir por ella. Dada la importancia que tiene en el estudio de esta novela, y puesto que su corta extensión lo permite, reproduzco a continuación el texto, acompañado de la traducción de García Jurado (la cita que recoge Maturin está en negrita):

Et mihi discendi et tibi docendi facultatem otium praebet. Igitur perquam uelim scire, esse phantasmata et habere propriam figuram numenque aliquod putes an inania et uana ex metu nostro imaginem accipere (...).

Erat Athenis spatiosa et capax domus sed infamis et pestilens. Per silentium noctis sonus ferri, et si attenderes acrius, strepitus uinculorum longius primo, deinde e proximo reddebatur: mox apparebat idolon, senex macie et squalore confectus, promissa barba horrenti capillo; cruribus compedes, manibus catenas gerebat quatiebatque. Inde inhabitantibus tristes diraeque noctes per metum uigilabantur; uigiliam morbus et crescente formidine mors sequebatur. Nam interdiu quoque, quamquam abscesserat imago, memoria imaginis oculis inerrabat, longiorque causis timoris timor erat. Deserta inde et damnata solitudine domus totaque illi monstro relicta; proscribebatur tamen, seu quis emere seu quis conducere ignarus tanti mali uellet.

Venit Athenas philosophus Athenodorus, legit titulum auditoque pretio, quia suspecta uilitas, percunctatus omnia docetur ac nihilo minus, immo tanto magis conducit. Vbi coepit aduesperascere, iubet sterni sibi in prima domus parte, poscit pugillares stilum lumen, suos omnes in interiora dimittit; ipse ad scribendum animum oculos manum intendit, ne uacua mens

5 «Aparecía la imagen de un anciano». La traducción es mía.

${ }^{6}$ Este texto, como indica W. M. S. Russell (1981:209), fue escolar durante un tiempo («The most famous ancient ghost store of al lis told in Pliny the Younger's letter about ghosts, which I mentioned earlier; generations of schoolchildren have had to translate it»), e incluso aparece citado como ejemplo en uno de los manuales básicos de la segunda mitad del siglo XIX, The Revised Latin Primer, de Kennedy. En esta gramática se recoge justamente la continuación de la cita que ha escogido Maturin: «senex promissa barba, horrenti capillo» (Kennedy, 1888:129). 
audita simulacra et inanes sibi metus fingeret. Initio, quale ubique, silentium noctis; dein concuti ferrum, uincula moueri. Ille non tollere oculos, non remittere stilum, sed offirmare animum auribusque praetendere. Tum crebrescere fragor, aduentare et iam ut in limine, iam ut intra limen audiri. Respicit, uidet agnoscitque narratam sibi effigiem. Stabat innuebatque digito similis uocanti. Hic contra ut paulum exspectaret manu significat rursusque ceris et stilo incumbit. Illa scribentis capiti catenis insonabat. Respicit rursus idem quod prius innuentem, nec moratus tollit lumen et sequitur. Ibat illa lento gradu quasi grauis uinculis. Postquam deflexit in aream domus, repente dilapsa deserit comitem. Desertus herbas et folia concerpta signum loco ponit.

Postero die adit magistratus, monet ut illum locum effodi iubeant. Inueniuntur ossa inserta catenis et implicita, quae corpus aeuo terraque putrefactum nuda et exesa reliquerat uinculis; collecta publice sepeliuntur. Domus postea rite conditis manibus caruit (Plin.Ep.7.27.1-11).

\section{Traducción:}

La falta de ocupaciones a mí me brinda la oportunidad de aprender y a ti la de enseñarme. De esta forma, me gustaría muchísimo saber si crees que los fantasmas existen y tienen forma propia, así como algún tipo de voluntad, o, al contrario, son sombras vacías e irreales que toman imagen por efecto de nuestro propio miedo (...).

Había en Atenas una casa espaciosa y grande, pero tristemente célebre e insalubre. En el silencio de la noche se oía un ruido y, si prestabas atención, primero se escuchaba el estrépito de unas cadenas a lo lejos, y luego ya muy cerca: a continuación aparecía una imagen, un anciano consumido por la flacura y la podredumbre, de larga barba y cabello erizado; grilletes en los pies y cadenas en las manos que agitaba y sacudía. A consecuencia de esto, los que habitaban la casa pasaban en vela tristes y terribles noches a causa del temor; la enfermedad sobrevenía al insomnio y, al aumentar el miedo, la muerte, pues, aun en el espacio que separaba una noche de otra, si bien la imagen desaparecía, quedaba su memoria impresa en los ojos, de manera que el temor se prolongaba aún mas allá de aquello que lo causaba. Así pues, la casa quedó desierta y condenada a la soledad, dejada completamente a merced de aquel monstruo; no obstante se había puesto en venta, por si alguien, no enterado de tamaña calamidad, quisiera comprarla o tomarla en alquiler.

Llega a Atenas el filósofo Atenodoro, lee el cartel y una vez enterado del precio, como su baratura era sospechosa, le dan razón de todo lo que pregunta, y esto, lejos de disuadirle, le anima aún más a alquilar la casa. Una vez comienza a anochecer, ordena que se le extienda el lecho en la parte delantera, pide tablillas para escribir, un estilo, y una luz; a todos los suyos les aleja enviándoles a la parte interior, y él mismo dispone su ánimo, ojos y mano al ejercicio de la escritura, para que no estuviera su mente desocupada y el miedo diera lugar a ruidos aparentes e irreales. Al principio, como en cualquier parte, tan sólo se percibe el silencio de la noche, pero después la sacudida de un hierro y el movimiento de unas cadenas: el filósofo no levanta los ojos, ni tampoco deja su estilo, sino que pone resueltamente su voluntad por delante de sus oídos. Después se incrementa el ruido, se va aproximando y ya se percibe en la puerta, ya dentro de la habitación. Vuelve la vista y reconoce al espectro que le habían descrito. Éste estaba allí de pie y hacía con el dedo una señal como llamándole. El filósofo, por su parte, le indica con su mano que espere un poco, y de nuevo se pone a trabajar con sus tablillas y estilo, pero el espectro hacía sonar sus cadenas para atraer su atención. Éste vuelve de nuevo la cabeza y ve que hace la misma seña, así que ya sin hacerle esperar coge el candil y le sigue. Iba el espectro con paso lento, como si le pesaran mucho las cadenas; después bajó al patio de la casa, y de repente, desvaneciéndose, abandona a su acompañante. El filósofo recoge hojas y hierbas y las coloca en el lugar donde ha sido abandonado a manera de señal. 
Al día siguiente acude a los magistrados y les aconseja que ordenen cavar en aquel sitio. Se encuentran huesos insertos en cadenas y enredados, que el cuerpo, putrefacto por efecto del tiempo y de la tierra, había dejado desnudos y descarnados junto a sus grilletes. Reunidos los huesos se entierran a costa del erario público. Después de esto la casa quedó al fin liberada del fantasma, una vez fueron enterrados sus restos convenientemente (traducción de García Jurado, 2002: 57-60).

La aparición de fantasmas exigiendo un enterramiento digno (como el caso que relata Plinio) o alguna ofrenda era una creencia muy extendida entre los latinos, así como en otras muchas culturas de la Antigüedad. Pertenece al folklore popular antes que a la literatura, y es en este contexto antropológico como debe entenderse. Entre otros autores, esta creencia en los fantasmas ha sido recogida por Ovidio en los Fastos, donde el poeta latino recuerda una época en que, debido a las guerras, se descuidaron las ofrendas a los antepasados muertos, y éstos se levantaron de sus tumbas recordando las obligaciones que debían cumplirse ${ }^{7}$. Literariamente, Plauto y Luciano también recogen una historia similar, en la Mostellaria (Pl.Most.468-505) y en Philopseudeis (Luc.Philops.30-31), respectivamente.

Antes de Maturin, la carta de Plinio ya había sido recogida de forma explícita por Jan Potocki (1761-1815) en su novela Manuscrit trouvé à Saragosse (1804-1805), donde el escritor polaco ofrecía una traducción completa del texto. Además de la obra de Potocki, García Jurado (2002) señala también en otras novelas previas la presencia implícita de algunos motivos que habían sido fijados en el texto de Plinio, como la descripción del fantasma, sus movimientos o su interacción con otro personaje que, frente al ser sobrenatural, representa la razón. En este sentido, las novelas de The Castle of Otranto, de Horace Walpole, o The Monk, de Matthew Gregory Lewis, pueden considerarse también vías de transmisión de la carta de Plinio dentro del género gótico, y sus autores deben entenderse como intermediarios que han puesto en contacto la Antigüedad con las nuevas tendencias románticas. También resulta especialmente sorprendente la obra pictórica del poeta visionario William Blake, que en uno de sus grabados («Nebukadnezar», 1795) representa al rey Nabucodonosor II caracterizado con rasgos muy similares a los del fantasma de Plinio: un anciano consumido, lleno de harapos y con una larga barba. Entre estas obras y estos autores, Melmoth, the Wanderer, de Charles Robert Maturin, es el colofón de una

\footnotetext{
7 "Est honor et tumulis, animas placare paternas, / parvaque in exstructas munera ferre pyras. / Parva petunt manes: pietas pro divite grata est munere; / (...) at quondam, dum longa gerunt pugnacibus armis / bella, Parentales deservere dies. / non impune fuit; nam dicitus omine ab isto / Roma suburbanis incaluisse rogis. / vix equidem credo: bustis exisse feruntur / et tacitae questi tempore noctis avi, / perque vias Urbis latosque ululasse per agros / deformes animas, volgus inane, ferunt. / post ea praeteriti tumulis redduntur honores, / prodiisque venit funeribusque modus) (Ov. Fast. 2.533-556) ("También las tumbas tienen su honor. Aplacad las almas de los padres y llevad pequeños regalos a las piras extintas. Los manes reclaman cosas pequeñas; agradecen el amor de los hijos en lugar de los regalos de los ricos. (...) Mas hubo una época, mientras libraban largas guerras con las armas batalladoras, en la cual hicieron omisión de los días de los muertos. No quedó esto impune, pues dicen que, desde aquel mal agüero, Roma se calentó con las piras de los suburbios. Apenas puedo creerlo; dicen que nuestros abuelos salieron de sus tumbas, quejándose en el transcurso de la noche silenciosa. Dicen que una masa vacía de almas desfiguradas recorrió aullando las calles de la ciudad y los campos extensos. Después de ese suceso, se reanudaron los honores olvidados de las tumbas, y hubo coto para los prodigios y los funerales”, Ovidio, 1988:82-83. Traducción de Segura Ramos).
} 
tradición muy particular, que funciona de forma paralela a los ámbitos académicos. Teniendo esto en cuenta, no es extraño pensar que, junto a aquellos que estaban más versados en los estudios clásicos, el texto de Plinio también podía ser fácilmente reconocido por los aficionados a la literatura gótica. Quizá por eso Maturin decidió no especificar a qué Plinio pertenecía la cita, haciendo así un guiño a todos aquellos lectores conscientes de esta tradición literaria.

Como indica García Jurado (2008a), el término «eidolon» de la frase de Plinio cita-

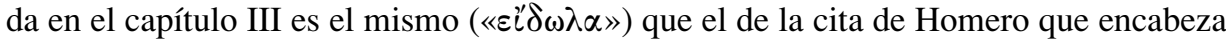
los capítulos VI y XXV:

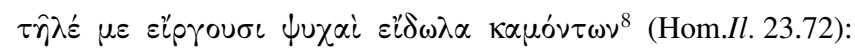

Pero, además de este paralelismo léxico, existe un paralelismo de contenido entre los dos textos. La cita de Homero corresponde al canto IV de la Ilíada, y está puesta en boca de un fantasma; se trata de Patroclo que, como el fantasma de Plinio, se aparece en sueños a Aquiles y le pide que le dé correcta sepultura para que pueda entrar en el Hades:

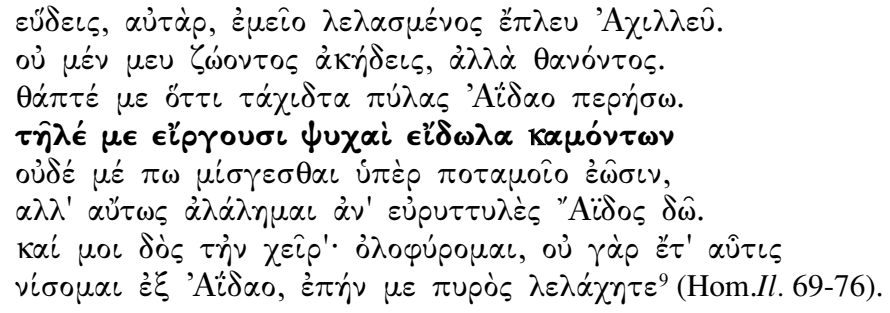

Ambos textos, por tanto, representan a un fantasma que se dirigen a un vivo para pedir un enterramiento correcto.

La cita de Homero y el pasaje de donde se extrae es muy semejante a otro texto clásico que también cita Maturin, y que corresponde a la Eneida. En el capítulo X de Melmoth, the Wanderer, el capítulo II del poema de Virgilio aparece en plena narración, donde se convierte en pesadilla de Alonso Moncada. La escena que se recoge es el momento en que Héctor se aparece en sueños a Eneas y le advierte sobre el incendio que va a producirse, instándole asimismo a que se marche con su pueblo en búsca de una nueva ciudad. El pasaje es el siguiente:

I thought I was a boarder in it, and studying Virgil. I was reading that passage in the second book, where the vision of Hector appears to Æneas in his dream, and his ghastly and dishonoured form suggests the mournful exclamation,

\footnotetext{
8 «Lejos de sí me retienen las almas, las sombras de los difuntos» (traducción de Crespo Güenes, 2000:455).

9 «Estas durmiendo y ya te has olvidado de mí, Aquiles. En vida nunca te descuidaste, pero sí ahora que estoy muerto. Lejos de sí me retienen las almas, las sombras de los difuntos, que no me permiten unirme a ellas al otro lado del río, y en vano vago por la mansión de vastas puertas, de Hades. Dame también la mano, lo pido por piedad. Pues ya no volveré a regresar del Hades cuando me hagáis partícipe del fuego» (traducción de Crespo Güenes, 2000:455).
} 
- - Heu quantum mutatus ab illo,-

-Quibus ab oris, Hector expectate venis?

Then I thought Juan was Hector, - that the same pale and bloody phantom stood calling me to fly- 'Heu fuge,' while I vainly tried to obey him. Oh that dreary mixture of truth and delirium, of the real and visionary, of the conscious and unconscious parts of existence, that visits the dreams of the unhappy! He was Pantheus, and murmured,

'Venit summa dies, et ineluctabile tempus.'

I appeared to weep and struggle in my dream. I addressed the figure that stood before me sometimes as Juan, and sometimes as the image of the Trojan vision. At last the figure uttered, with a kind of querulous shriek, —-that vox stridula which we hear only in dreams,

\section{'Proximus ardet Ucalegon'}

and I started up fully awake, in all the horrors of an expected conflagration ${ }^{10}$ (Maturin, 1968:218-219).

Todos los versos de Virgilio que recoge Maturin en este pasaje, incluso los dos primeros, que aparecen juntos, corresponden a momentos diferentes dentro del poema latino. No obstante, a pesar de estar separados en el texto original, el orden en que los dispone Maturin les da pleno sentido, y resume los dos temas más importantes de la escena: la aparición del fantasma de Héctor y el incendio, dos hechos que se trasladan a la novela de Maturin:

1. Heu quantum mutatus ab illo $\rightarrow$ verso 274 (heu no aparece en este verso): «Ay, cuán diferente de aquél»

2. Quibus ab oris, Hector expectate venis ? $\rightarrow$ versos 282-283 (está mal el orden de palabras: quibus Hector ab oris expectate venis): «¿De qué orillas vuelves, Héctor, hasta el que te espera?»

10 «Soñé que era interno y que estudiaba a Virgilio. Leía este pasaje del Libro Segundo en el que el espectro de Héctor se aparece a Eneas, y su forma horrible e infamada suscita la dolida exclamación:

\section{Heu quantum mutatus ab illo, \\ Quibus ab oris, Hector expectate venis?}

Luego soñé que Juan era Héctor; que el mismo fantasma, pálido y sangriento, se alzaba gritándome que huyera: 'Heu fuge'; mientras yo intentaba en vano obedecerle. ¡Oh, qué lúgubre mezcla de veracidad y delirio, de realidad e ilusión, de elmentos conscientes e inconscientes de la existencia, visita los sueños de los desventurados! Él era Panteo, y murmuraba:

Venit summa dies, et ineluctabile tempus

Al parecer, lloraba y me debatía en mi sueño. Me dirigía a la figura que estaba ante mí unas veces como Juan, y otras como la imagen de la visión troyana. Por último, la figura exclamó, con una especie de alarido quejumbroso en esa vox stridula que sólo oímos en sueños

\section{Proximus ardet Ucalegon}

Y me levanté completamente despierto, con todos los horrores del que espera ver un incendio» (Maturin, 2005:425-426). Todas las traducciones del texto de Maturin son de Torres Oliver (2005). 
3. Venit summa dies, et ineluctabile tempus $\rightarrow$ verso 324: «Llega el último día y la hora inevitable»

4. Proximus ardet Ucalegon $\rightarrow$ versos 311-312: «Cerca arde ya Ucalegón»

5. Después de los dos primeros versos, Alonso Moncada incluye en su discurso un $\mathrm{Heu}$, Fuge!, que corresponde al verso 289.

En el texto de Virgilio de nuevo aparece un fantasma (Héctor) hablando a un vivo (Eneas) para hacerle una petición. Y, como en el caso de Homero, también aquí se presenta en un sueño y el escenario es la guerra de Troya. Dos fantasmas épicos, por tanto, entran con sus armas en la ficción gótica. La cita de Virgilio, por otra parte, no acaba en sí misma, sino que continúa en el capítulo XI, donde tiene lugar el incendio al que se alude (esta vez en el monasterio, en lugar de en Troya):

It was on the night of the 29th November 17-, that this extraordinary cicumstance took place ... On the first intimation that the fire was spreading rapidly, and threatened danger, the prisoners were ordered to be brought from their cells, and guarded in a court of the prison ... The heavens were on fire - and the torches, held no longer in firm hands, gave a tremulous and pallid light ${ }^{11}$ (Maturin, 1968:240).

Como hemos podido comprobar, tres textos clásicos y tres fantasmas convergen en la novela de Maturin, que muestra un gran interés por lo sobrenatural en la literatura grecolatina. Y los tres textos se van enlazando unos con otros, como si de una cadena se tratase. El texto de Plinio muestra a un fantasma que se aparece para exigir un enterramiento digno; ésta es también la petición del fantasma de Patroclo, que se aparece en sueños a Aquiles; y, finalmente, también en sueños se aparece Héctor a Eneas, para advertirle sobre el incendio de Troya (un incendio que finalmente se materializa en el mismo monasterio). Nótese que Moncada está igualmente dormido, como Aquiles y como Eneas, en el momento de la visión, una circunstancia que confirma el paralelismo entre todos estos textos. De esta forma, por medio de diferentes eslabones, relaciona el texto de Plinio con el de Homero, y éste con el de Virgilio. Consigue crear así la siguiente red literaria, que conectan una parte muy importante de la tradición clásica de la novela de Maturin:

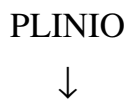

FANTASMA $1 \quad \infty$

Aparición

Enterramiento

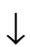

ANCIANO
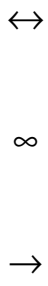

$=$

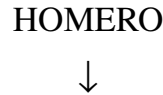

FANTASMA 2

Sueño

Enterramiento

$\downarrow$

PATROCLO

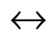

$\infty$

$\rightarrow$

$=$
VIRGILIO

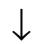

FANTASMA 3

Sueño

Advertencia

$\downarrow$

HÉCTOR

11 «La noche del 29 de noviembre de 17... fue cuando tuvo lugar tan extraordinario suceso; (...) A la primera voz de que el fuego se propagaba rápidamente y amenazaba peligro, se ordenó sacar a los prisioneros de sus celdas y que fueran custodiados en un patio de la prisión. (...) El cielo se veía en llamas, y las antorchas, sostenidas pro manos ya no firmes, difundían una luz pálida y temblorosa» (Maturin, 2005:467-468). 
Dentro de este esquema, el único relato que, retrospectivamente, podríamos identificar como «gótico» es el de Plinio, el más tardío y marginal. Ni la escena de Homero ni la de Virgilio son propiamente «sobrenaturales» (pues la aparición de fantasmas en sueños se aceptaba de una forma tan natural como la participación de los dioses en el campo de batalla), ni producen el mismo terror que el anciano consumido y harapiento. Sin embargo, a la luz del texto de Plinio, las otras dos escenas adquieren el halo misterioso y sobrecogedor propio de los relatos góticos. La misma estructura de la novela confirma esta supeditación de Homero y Virgilio a Plinio, que aparece en primer lugar (capítulo III), no sólo delante de los otros dos autores (Homero en el capítulo VI, Virgilio en el capítulo X), sino de todas las referencias al mundo clásico, algunas de las cuales quedan también teñidas por el mismo ambiente estremecedor. Este orden Plinio-Homero-Virgilio se mantiene en otras apariciones de los autores en la novela, confirmando en un nivel textual la conexión argumental de los tres relatos. Como citas iniciales, Maturin utiliza sus textos en los capítulos III (Plinio), VI (Homero) y VII (Virgilio). En el capítulo XXIII, como veremos más adelante, reaparece en la narración la primera cita de Plinio, y de nuevo los capítulos XXV y XXVII son introducidos por Homero y Virgilio, respectivamente. Nótese, igualmente, la proximidad de las citas, concentradas en dos partes de la novela muy concretas (del capítulo III al VII y del capítulo XXIII al XXVII). Los tres fantasmas quedan así indisolublemente unidos, revelando el lado más oscuro de la literatura clásica. De los tres textos, el relato de Plinio ocupa un lugar preeminente, y a él dedicaremos los próximos apartados.

\section{Desarkollo de la cita. El fantasma de Maturin}

En Melmoth, the Wanderer, la cita de Plinio describiendo el fantasma abre el capítulo en el que John Melmoth lee el manuscrito que le había legado su tío y que contiene la historia de Stanton. Este capítulo nos descubre la maldad del personaje de Melmoth, que apareció por primera vez misteriosamente en la habitación del tío de John. En ambos relatos, por tanto, la narración presenta un ser sobrenatural: Melmoth (en la novela de Maturin) o el fantasma (en la carta de Plinio). Pero ésta no es más que la primera identificación entre las dos historias, que tendrán otros paralelismos. Veamos, a continuación, cómo traslada Maturin la cita de Plinio, y, en general, todo el ambiente del mundo clásico a la ficción.

Como en otras muchas novelas góticas, la acción tiene lugar en España, crisol de las culturas romana y musulmana. Maturin aprovecha este escenario para recrearse en la sublimidad del paisaje y la evocación de tiempos pasados, haciéndose eco de los motivos más típicos del género. Sus reflexiones indagan en los puentes que unen la época antigua con la contemporánea, así como en el significado de la civilización romana para el mundo moderno:

The magnificent remains of two dynasties that had passed away, the ruins of Roman palaces, and of Moorish fortresses, were around and above him; ... The difference between the architecture of the Roman and Moorish ruins struck him. Among the former are the remains of a theater, and something like a public place; the latter present only the remains of fortresses, embattled, castellated, and fortified from top to bottom, - not a loophole for pleasure to get in by, - the loopholes were only for arrows; all denoted military power and despotic subjugation a l'outrance. The contrast might have pleased a philosopher, and he might have indulged in the 
reflection, that though the ancient Greeks and Romans were savages (as Dr. Johnson says all people who want a press must be, and he says truly), yet they were wonderful savages for their time, for they alone have left traces of their taste for pleasure in the countries they conquered, in their superb theaters, temples (which were also dedicated to pleasure one way or another), and baths, while other conquering bands of savages never left anything behind them but traces of their rage for power. So thought Stanton, as he still saw strongly defined, though darkened by the darkening clouds, the huge skeleton of a Roman amphitheater, its arched and gigantic colonnades now admitting a gleam of light, and now commingling with the purple thunder cloud; and now the solid and heavy mass of a Moorish fortress, no light playing between its impermeable walls, — the image of power, dark, isolated, impenetrable ${ }^{12}$ (Maturin, 1968:29).

En este pasaje Maturin demuestra que su novela está muy lejos de oponerse a la estética clásica, y que, por el contrario, homenajea a la cultura grecolatina. Por eso, Maturin no tiene ningún reparo en evocar la Antigüedad romana como imagen de sublimidad, una de las categorías estéticas reivindicadas en la novela gótica. Para ello escoge uno de los símbolos más recurrentes dentro de la literatura gótica: la ruina. La ruina es la prueba viviente de que, por muy grandiosa y sublime que una civilización haya llegado a ser, al final siempre hay destrucción y muerte:

But he ceased to forget these local and petty dangers, as the sublimity of romance would term them, when he saw the first flash of the lightning, broad and red as the banners of an insulting army whose motto is Vae victis, shatter to atoms the remains of a Roman tower; - the rifted stones rolled down the hill, and fell at the feet of Stanton. ... He stood and saw another flash dart its bright, brief, and malignant glance over the ruins of ancient power, and the luxuriance of recent fertility. Singular contrast! The relics of art forever decaying, - the productions of nature forever renewed-. (Alas! for what purpose are they renewed, better than to mock at the perishable monuments which men try in vain to rival them by.) The pyramids themselves must perish, but the grass that grows between their disjointed stones will be renewed from year to year ${ }^{13}$ (Stanton, 1968:30).

12 «Los espléndidos vestigios de dos dinastías desparecidas: las ruinas de los palacios romanos y de las fortalezas musulmanas, se alzaban a su alrededor y por encima de él; (...) Le impresionaba la diferencia arquitectónica entre las ruinas romanas y las musulmanas. Entre las primeras estaban los restos de un teatro y algo así como una plaza pública; las segundas consistían sólo en fragmentos de fortalezas almenadas, encastilladas, fortificadas de pies a cabeza sin una mala abertura por donde entrar con comodidad..., las únicas aberturas eran sólo aspilleras para las flechas; todo denotaba poder militar, y despótico sometimiento a l'outrance. El contraste habría encantado a un filósofo, quien se habría entregado a la reflexión de que, si bien los griegos y los romanos fueron salvajes (como dice acertadamente el doctor Jonson que debe ser todo pueblo que quiere aprovecharse de algo), fueron unos salvajes maravillosos para su tiempo, ya que sólo ellos han dejado vestigios de su gusto por el placer en los países que conquistaron, mediante sus soberbios teatros, templos (igualmente dedicados, de una manera u otra, al placer) y termas, mientras que otras bandas salvajes de conquistadores no dejaron jamás tras ellos otra cosa que las huellas de su avidez por el poder. En eso pensaba Stanton mientras contemplaba, vigorosamente recortado, aunque oscurecido por las sombrías nubes, el inmenso esqueleto de un anfiteatro romano, sus gigantescos peristilos coronados con arcos, recibiendo unas veces un destello de luz, otras, mezclándose con el púrpura de la nube cargada de electricidad; y luego, la sólida y pesada mole de una fortaleza musulmana, sin una luz entre sus impermeables murallas, una oscura, aislada, impenetrable imagen del poder» (Maturin, 2005:63-64).

13 «(...) Pero cesó de tener en olvido estos locales e insignificantes peligros, como la sublimidad de la ficción podría definirlos, cuando vio el primer relámpago, ancho y rojo como el pendón de un ejército insolente con la divisa Vae victis!, reducir a polvo los restos de una torre romana; las rocas hendidas rodaron monte abajo y llegaron hasta los pies de Stanton. (...) Siguió inmóvil, y vio el reflejo brillante, breve y maligno de otro relámpa- 
El pasaje es en sí mismo muy simbólico. No anula la anterior admiración que había sentido Stanton ante la contemplación del Imperio Romano, pero acaba con las ínfulas de inmortalidad que le hace parecer superior al resto de las culturas. Como un siervo a su general en medio de la celebración del triunfo, la literatura gótica parece decirle al oído a Roma: «Respice post te! Hominem te memento» ${ }^{14}$.

Tras esta primera presentación de la civilización clásica, Maturin comienza su relato sobre Melmoth, que, como se ha dicho antes, es paralelo a la historia de fantasmas de Plinio. Al igual que el filósofo Atenodoro, cuando Staton llega al pueblo percibe algo extraño, que va más allá de las apariencias: en el caso de Atenodoro, se trata de la baratura de una casa en alquiler («Venit Athenas philosophus Athenodorus, legit titulum auditoque pretio, quia suspecta vilitas, percunctatus omnia docetur ac nihilo minus, immo tanto magis conducit», Plin.Ep.7.27.7); Stanton, en cambio, advierte un particular miedo (concretamente hacia los ingleses) que se ha apoderado de todo el vecindario ( «Stanton felt there was something more than nacional bigotry in the exclamations of the old woman; there was a peculiar and personal horror of the English -and he was right $\gg^{15}$, Maturin, 1968:31). En los dos relatos el miedo se acentúa por la presencia de la noche, lo que ya se ha convertido en un tópico de la literatura gótica (Plin.Ep.7.27.5: «per silentium noctis sonus ferri (...)»; Maturin, 1968:31: «The terrors of the night rendered Stanton a sturdy and an appeasable applicant» ${ }^{16}$ ). Pero uno de los paralelismos más importantes entre la novela de Maturin y el relato de Plinio está en la descripción del escenario. «Erat Athenis spatiosa et capax domus, sed infamis et pestilens (...). Deserta inde et damnata solitudineque domus totaque illi monstro relicta», escribió Plinio (Plin.Ep.7.27.5-6) en su carta. En el manuscrito de John Melmoth se lee, aislada entre dos lagunas del texto, la siguiente frase: «The house was handsome and spacious, but the melancholy appearance of desertion...» ${ }^{17}$ (Maturin, 1968:31). Como señala García Jurado (2002:61n), «hay una tipología común y lógica para las casas tomadas por fantasmas, ya que han de ser antiguas y grandes»; sin embargo, la frase de Maturin es más que un simple topos, pues se relaciona de forma directa, y posiblemente sin ningún otro mediador literario, con la carta de Plinio. Así parece indicarlo el destacado lugar de la frase, separada totalmente del resto del texto, el paralelismo sintáctico que guarda con la primera frase del relato de Plinio (dos atributos unidos por una conjunción copulativa y seguidos de una oración adversativa que da a entender cierto aire de misterio), y las dos principales características de la casa: espaciosa y abandonada. Además, la cita inicial con la que se abría el capítulo no deja lugar a equívocos, y demuestra que Maturin no sólo conocía el texto de Plinio, sino que lo utilizó como «hipotexto» para escribir el ca-

go por encima de las ruinas del antiguo poderío, y la exuberancia de toda la vegetación. ¡Singular contraste! Las reliquias del arte en perpetuo deterioro... y las producciones de la naturaleza en eterna renovación (¡Ah, con qué propósito se renuevan, sino para burlarse de los perecederos monumentos con los que los hombres tratan de rivalizar!) Las mismas pirámides deben perecer; en cambio, la yerba que crece entre sus piedras descoyuntadas se renovará año tras año» (Maturin, 2005:64-65).

${ }^{14}$ Frase que, según Tertuliano (Apologetico, 33. 15), se decía a los emperadores durante la celebración de una victoria.

15 «Stanton intuía que había algo más que un mero fanatismo nacional en las exclamaciones de la anciana; había un extraño y personal horror por el inglés... y estaba en lo cierto» (Maturin, 2005:67).

16 «Los terrores de la noche hicieron de Stanton un enérgico e insistente suplicante» (Maturin, 2005:66-67).

17 «La casa era hermosa y espaciosa, pero el melancólico aspecto de abandono...» (Maturin, 2005:67). 
pítulo III de su novela. Todo este escenario literario y lingüístico precede a la aparición de Melmoth, que debe entenderse, en consecuencia, como un trasunto del fantasma de Plinio.

Maturin no oculta en ningún momento la existencia de una tradición de historias de fantasmas y seres sobrenaturales en casas encantadas, e incluso lo «confiesa» al lector más perspicaz: «Stanton paused, and fearful images of the dangers to which travellers on the Continent are exponed in deserted and remote habitations, came into his mind ${ }^{18}$ (Maturin, 1968:32). Tras estas primeras descripciones, se cuenta la historia terrible que ocurrió en esta casa, el día en que sus dueños, una pareja de recién casados, celebraron allí el banquete de su boda. Aunque ellos no se dieron cuenta, en el banquete, que fue seguido de un baile de máscaras, estaba una persona que no había sido invitada. Se trataba de Melmoth, el errabundo, que deja desesperación y tormentos allí por donde pasa. El primero en advertirlo fue el padre Olavide, que reconoció al emisario del demonio en este asistente a la fiesta. El padre Olavide era una de las personas más respetadas, y el confesor de la familia anfitriona. De él se decía que era el peor enemigo del diablo, quien «when he was so contumacious as to resist Latin, and even the first verses of the Gospel of St John in Greek, which the good Father never had recourse to but in cases of extreme stubbornness and difficulty ... then he always applied to the Inquisition ${ }^{19}$ (Maturin, 1968:34) ${ }^{20}$. El enfrentamiento entre Olavide y Melmoth, lleno de tensión y de terror psicológico, acaba con la muerte del sacerdote ${ }^{21}$ y con la muerte de la joven novia en extrañas circunstancias (no determinadas debido a la mala conservación que Maturin atribuye al manuscrito). Después de estos desgraciados acontecimientos, el novio «never recovered his reason» y la familia «deserted the mansion rendered terrible by so many misfortunes» ${ }^{22}$ (Maturin, 1968:36). Así termina la primera parte del capítulo, y, con ella, la intertextualidad que éste desarrolla con el relato de Plinio.

18 «Stanton se detuvo, y le vinieron al pensamiento imágenes espantosas de los peligros a que se exponen los viajeros del continente en las moradas deshabitadas y remotas» (Maturin, 2005:68).

19 «Cuando se resistía contumaz al latín, e incluso a los primeros versículos del Evangelio de San Juan en griego, al que no recurría el buen padre si no era en casos de extrema obstinación y dificultad (...) apelaba siempre a la Inquisición» (Maturin, 2005:71).

${ }^{20}$ Resulta muy interesante este uso del latín y el griego para el exorcismo o cualquier práctica que ayude a entrar en comunicación con lo sobrenatural. Independientemente del contenido de las palabras, las lenguas clásicas parecen tener un poder para invocar a los espíritus que no tienen las lenguas vernáculas. Es posible que esto se deba, en parte, al mismo comportamiento supersticioso que despertaba la escritura en las civilizaciones primitivas, cuando sólo unos pocos conocían el alfabeto. No cabe duda de que el desconocimiento crea inseguridad y temor, y más aún cuando se trata de un lenguaje ininteligible (o reservado a una élite), como el latín y el griego empezaban a ser en el siglo XVIII. El latín y el griego como lenguas de comunicación con seres sobrenaturales ha pasado a ser ya un motivo más del género, que se sigue repitiendo en las nuevas producciones literarias y cinematográficas, como El Exorcista (1973).

${ }^{21}$ Que tiene lugar fuera de escena, como Horacio recomienda para las tragedias.

22 «Nunca recobró el juicio»; «abandonó la mansión, tan terrible para ellos por tantas desventuras» (Maturin, 2005:75). 


\section{La doble cita. El teXto de Plinio como Protagonista de la novela de Maturin}

La carta de Plinio vuelve a aparecer otra vez en el capítulo XXIII. Este capítulo se centra en la correspondencia que mantienen Doña Clara y su marido Don Francisco de Aliaga, padres de Imalee (o Isidora, según su nombre cristiano), sobre su hija y su futuro matrimonio con Don Gregorio Montilla. La referencia al texto de Plinio no es una mera perla erudita del narrador, sino que se extrae directamente de un libro que forma parte del escenario. Por lo que cuenta Don Francisco, el libro es una especie de antología de cuentos de fantasmas de la Antigüedad clásica, donde se incluye también a Artemidoro (siglo II d. C.), autor griego del tratado sobre sueños más antiguo que se conserva: la Oneirokritiká ${ }^{23}$. Leyendo esta colección de textos, Don Francisco se quedó dormido. En una de las cartas le cuenta a su mujer la experiencia que tuvo después, cuando despertó y se encontró con lo que parecía un fantasma que tenía unos rasgos semejantes a los de Imalee, de acuerdo con las descripciones que se le habían dado de ella. Es entonces cuando aparece de nuevo la cita que abría el capítulo III, pero esta vez ligeramente ampliada e insertada dentro de la narración:

Now, whether it was the company I fortuned to be into, (whose conversation must never be known but to thee only), or the book I had been reading, which contained certain extracts from Pliny, Artemidore, and others, full-filled with tales which I may not now recount, but which did relate altogether to the revivification of the departed, appearing in due accordance with our Catholic conceptions of Christian ghosts in purgatory, with their suitable accoutrements of chains and flames, — as thus Pliny writeth, 'Apparebat eidolon senex, macie et senie confectus' —or finally, the weariness of my lonely journey, or other things I know not, -but feeling my mind ill-disposed for deeper converse with books or my own thoughts, and though oppressed by sleep, unwilling to retire to rest, ... I took out thy letters from the desk in which I duly reposit them, and read over the description which thou didst send me of our daughter ... So, thinking on those dark-blue eyes, —and those natural ringlets ... I dozed as I sat in my chair; and my dreams taking part with my waking thoughts, I was a-dreamt that such a creature, so fair, so fond, so cherubic, sat beside me, and asked me blessing. As I bowed to give it, I nodded in my chair and I awoke ... There was a female seated opposite me, clad in a Spanish dress, but her veil flowed down to her feet. She sat, and seemed to expect that I should bespeak her first. 'Damsel', I said, 'what seekest thou —or why art thou here' The figure never raised its veil, nor motioned with hand or lip. Mine head was full of what I had heard and read of; and after making the sign of the cross, and uttering certain prayers, I approached that figure, and said, 'Damsel, what wantest thou?' - 'A father', said the form, raising its veil, and disclosing the identical features of my daughter Isidora, as described in thy numerous letters. Thou mayest well guess my consternation, which I might almost term fear, at the sight and words of this beautiful but strange and solemn figure. Nor was my perplexity and trouble diminished but increased, when the figure, rising and pointing to the door, through which she forthwith passed with a mysterious grace and incredible alacrity, uttered, in transitu, words like these: —'Save me! — save me! —lose not a moment, or I am lost! And I swear to thee, wife,

${ }^{23}$ Nótese que Maturin cita a un autor latino y a uno griego; asimismo, en las citas iniciales pone en relación también una latina (la de Plinio) y una griega (la de Homero). Parece que, por lo menos en lo que respecta a estos capítulos aquí comentados, Maturin ha decidido mantener en una proporción equilibrada las dos culturas que forman parte del mundo clásico. 
that while that figure sat or departed, I heard not the rustling of her garments, or the tread of her foot, or the sound of her respiration —only as she went out, there was a rushing sound as of a wind passing through the chamber, - and a mist seemed to hang on every object around me, which dispersed, - and I was conscious of heaving a deep sigh, as if a load had been removed from my breast ${ }^{24}$ (Maturin, 1968:381-383).

Esta segunda referencia al texto de Plinio constituye, junto con la primera, lo que García Jurado (2008b) ha denominado una «doble cita», un juego literario que confirma la importancia que tiene este texto en la novela de Maturin ${ }^{25}$. En esta ocasión, la cita contiene un error: la palabra incorrecta senie, en lugar de squalore, que había escrito Plinio. Como señala García Jurado (2008a), senie debería haber sido senio (ablativo de senium, 'vejez'), y posiblemente la terminación en —e se haya debido a una analogía con macie. Cabe preguntarse si la equivocación de Maturin ha sido o no inconsciente. En un principio, no parece haber razones que justifiquen la palabra senie como una opción personal de Maturin, por lo que posiblemente haya que pensar más en un fallo de memoria. Sin embargo, no hay que olvidar tampoco la dimensión creativa, que, en el campo de la cita latina, desarrolló con gran éxito Edgar Allan Poe en su famoso relato de «The Purloined Letter», donde inventó nada menos que un texto de Séneca (vid. Barrios y García Jurado, 2005).

Al igual que en el capítulo III, también ahora la cita de Plinio precede a la aparición de un ser sobrenatural. En un principio, el trasunto del fantasma de Plinio parece ser en esta ocasión la imagen de Imalee-Isidora, que se muestra a su padre en una última súplica

24 «Ahora bien, ya fuera por la compañía que el azar había querido depararme (cuya conversación no debe ser conocida jamás sino por ti solamente), o por el libro que había estado leyendo, el cual contenía extractos de Plinio, Artemidoro y otros, e historias que ahora no me es posible contar, pero que se referían a la revivificación de los difuntos, pareciendo en completo acuerdo con las concepciones católicas de nuestros espectros cristianos del purgatorio, con sus correspondientes pertrechos de cadenas y llamas, tal como Plinio dice que apparebat eidolon senex, macie et senie confectus, o en fin, por el cansancio de mi solitario viaje, o por alguna otra causa que yo no sé, pero sintiendo mi mente mal dispuesta para seguir un diálogo más profundo con los libros o con mis propios pensamientos, $y$, aunque acuciado por el sueño, sin ganas de retirarme a descansar (...), saqué mis cartas del escritorio (...) y leí la descripción que me enviaste de nuestra hija (...). Así que pensando en esos ojos de azul intenso y en esos rizos naturales (...) me quedé dormido en mi silla; y fundiéndose mis sueños con mis pensamientos vigiles, soñé que esa criatura tan pura, afectuosa y angelical estaba sentada a mi lado y me pedía mi bendición. Al acceder yo a ello, di una cabezada en mi silla y me desperté. (...) . Había una mujer sentada junto a mí, vestida a la usanza española, aunque su velo descendía hasta los pies. Estaba sentada y parecía esperar a que yo hablase primero. 'Damisela — dije — ¿qué buscas, o por qué estás aquí?'. La figura no se levantó el velo, ni movió mano ni boca. Yo tenía el cerebro lleno de las cosas que había leído y oído; y después de hacer el signo de la cruz y de pronunciar ciertas oraciones, me acerqué a la figura y dije 'Damisela, ¿qué es lo que quieres' 'Un padre', dijo la forma alzando su velo y revelando idénticas facciones a las de mi hija Isidora, tal y como tú me la describes en tus numerosas cartas. Fácilmente podrás adivinar mi estupor, que casi podría calificar de miedo, ante la visión y las palabras de esta hermosa pero extraña y solemne figura. Y no disminuyó mi turbación y perplejidad, sino que aumentó aún más cuando la figura, poniéndose en pie y señalando la puerta, la atravesó al punto con misteriosa gracia e increíble presteza, pronunciando in transitu estas palabras: ‘'Salvadme! ¡Salvadme!, ¡no os demoréis un instante, o estaré perdida! Y te juro, esposa, que durante el tiempo que esta figura estuvo sentada o desaparecía, no oí el susurro de sus ropas, ni el roce de sus pies, ni el sonido de su respiración... Sólo hubo, en el momento de desaparecer, un rumor como de viento que cruzase la cámara; y una niebla pareció envolver cada objeto que había a mi alrededor, la cual se disipó, y tuve conciencia de un ahogo, como si acabaran de quitarme un peso del pecho» (Maturin, 2005:737-738).

${ }_{25}$ Nótese que la cita de Homero, que tiene muchos puntos en común con la de Plinio, también se repite dos veces en la obra, aunque las dos veces funciona como cita inicial. 
por su salvación; pero, en realidad, no sabemos claramente quién es el fantasma. ¿Se trata verdaderamente de Imalee-Isidora? Resulta extraño, pues está viva en el momento de esta aparición, y por tanto no podría haberse personado como un espectro. ¿Es, entonces, una «proyección» de Imalee-Isidora? ¿Se trata del propio Melmoth, que intenta advertir una y otra vez a Don Francisco del peligro que él mismo representa para su hija? ¿O es quizá una jugada de la mente de Don Francisco, sugestionada por sus lecturas? Sea como sea, se trata de una presencia sobrenatural que ha sido inspirada por un texto clásico, que, como vemos, fijó muchas de las características del fantasma moderno: un ser etéreo que entra en contacto con una persona para pedir ayuda; esta petición suele estar relacionada con las circunstancias de su muerte (la pasada, en el texto de Plinio, o la futura, en la novela de Maturin), y, por tanto exige a la persona que interceda para lograr su salvación; finalmente, una vez aclarado su deseo, el fantasma desaparece.

El texto de Plinio es el verdadero protagonista de toda la escena. Al igual que en capítulo III, de nuevo es aquí el principal hipotexto del que se sirve Maturin para su narración. Como entonces, también aquí la recreación del texto es precedida por una cita; pero esta vez, en lugar de estar en el nivel marginal del paratexto (según terminología de Genette), la cita forma parte de la misma ficción. La referencia a un libro físico que contiene una selección de textos clásicos con temática sobrenatural es un guiño metaliterario. Con este guiño se confirma el interés de los escritores modernos por los aspectos tenebrosos de la literatura clásica, así como la existencia de una antología de textos grecolatinos que se transmite en la literatura gótica, donde sigue estando muy presente.

Por último, en lo que se refiere al uso retórico de la doble cita, parece que se trata de un juego recurrente en los relatos de ficción gótica, como ha demostrado García Jurado $(2008 b)^{26}$. Según éste, Maturin no es del todo consciente de las implicaciones que este juego tiene en su novela, debido, entre otras cosas, a la gran distancia que existe entre los dos capítulos donde aparece ${ }^{27}$. Sin embargo, como hemos podido ver, la cita crea cohesión dentro de la extensa novela de Maturin y da continuidad a la carta de Plinio como hipotexto, al margen de su intencionalidad literaria.

\section{CONCLUSIONES}

La literatura clásica es un elemento esencial en la intertextualidad de Melmoth, the Wanderer, obra que culmina el primer ciclo de la novela gótica en Inglaterra. De entre todas las citas y alusiones al mundo grecolatino que plagan la novela, con un alto nivel de erudición, hemos destacado tres, de Plinio, Homero y Virgilio, respectivamente. Las tres citas, relacionadas tanto estructuralmente como por su contenido, muestran la imagen de tres fantasmas (un anciano y dos fantasmas épicos, Patroclo y Héctor) que se dirigen a un personaje vivo con una petición o una advertencia. A partir de estos tres fantasmas clásicos, Maturin crea el marco para el fantasma moderno de su novela.

${ }^{26}$ Edgar Allan Poe o Marcel Schwob son otros autores que lo utilizan, aunque con diferente grado de consciencia (vid. González-Rivas Fernández y García Jurado, 2008).

${ }^{27}$ Por el contrario, Edgar Allan Poe ya sí parece hacer un uso muy intencionado de la doble cita, un juego que llegará incluso hasta autores como Stephen King (vid. García Jurado, 2008a:30-31). 
Ya en obras góticas anteriores (Lewis, Potocki) se había recreado el relato de fantasmas de Plinio, demostrando que también entre los clásicos podía recuperarse una estética gótica. En función de este texto, las escenas de Virgilio y de Homero citadas en Melmoth, the Wanderer adquieren también un aire de misterio, que, sin embargo, no tenían en sus obras de origen. Lo gótico se une con lo clásico, y esto es gracias a un doble proceso de relectura que debe hacer el lector del siglo XIX. Si bien es cierto que lo gótico hay que entenderlo como una manifestación cultural concreta que surge en el contexto histórico, social y político del siglo XVIII, la estética de misterio, terror y sublimidad que recupera ya había existido en épocas anteriores. Y aunque, por esta cuestión temporal, estas obras no pueden llamarse propiamente góticas, los autores románticos las conocen y las tienen en cuenta como un posible material adaptable a la literatura moderna. Ésta es la segunda lectura que Maturin hace de Plinio para incorporarlo en su novela; y este mismo proceso es también el que lleva a cabo en lo que podríamos llamar una «tercera lectura» de los textos de Homero y Virgilio, que se reinterpretan a la luz de la epístola de Plinio. Lecturas y relecturas que, al final, unen lo que parecía irreconciliable.

El fantasma de Plinio, además, funciona como hipotexto en la novela, y su sombra literaria aparece en los capítulos III y XXIII. Los dos capítulos están unidos estructuralmente por la misma cita del texto latino, inicial en el capítulo III, e insertada en la narración en el capítulo XXIII. Se crea así una suerte de «doble cita», que da cuenta de la trascendencia que tiene el relato de Plinio en la novela de Maturin. Señalado esto, se ha comprobado que los mismos capítulos desarrollan el relato de diferentes maneras, presentando a Melmoth e Imalee-Isidora, respectivamente, como trasuntos modernos del fantasma latino.

En definitiva, un hecho tan aparentemente aislado como una cita literaria puede ser la punta del iceberg que esconda un complejo sistema de relación entre literaturas. Éste es el caso de Maturin y los textos de Plinio, Homero y Virgilio. La relación entre estos autores y la variedad de lecturas que ofrecen y exigen demuestra que, lejos de ser opuestas, la literatura clásica y la literatura gótica se complementan, pues, al fin y al cabo, la fantasía no entiende de rivalidades.

\section{BIBLIOGRAFÍA CITADA}

\section{Estudios citados}

Barrios Castro, María José y García Jurado, Francisco (2005) «Nihil sapientiae odiosus acumine nimio: Séneca como máscara de Edgar Allan Poe», Ad amicam amicissime scripta: homenaje a la profesora María José López de Ayala y Genovés, Madrid, UNED, vol. 1, pp.409-418.

GARCíA JURADO, Francisco (2008a) «La literatura Antigua y modernos relatos de terror: la función compleja de las citas grecolatinas», Nova Tellus: Anuanodel Centro de Estudios Clásicos, tomo 50, n. ${ }^{\circ} 134$, pp. 169-204.

García JURADO, Francisco (2008b) «Las citas grecolatinas en los modernos relatos de terror: el fenómeno de la 'doble cita'», Cuadernos del abismo: Homenaje a H. P. Lovecraft, (Fernando Broncano y David Hernández de la Fuente, eds.), Literaturas.com Libros, Madrid.

GARCíA JURADO, Francisco (2006) «Los cuentos de fantasmas: entre la literatura clásica y el relato gótico» en la revista electrónica Culturas Populares, 2. URL: http://www.culturaspopulares. org/textos2/articulos/garciajurado.pdf. 
García JuRAdo, Francisco (2002) «La carta de Plinio el Joven sobre los fantasmas (Plin. 7,1 27, 511) releída como relato gótico», Exemplaria, 6, pp. 55-80.

GARCíA JuRADO, Francisco (2000) «Plinio y Virgilio: textos de la literatura latina en los relatos fantásticos modernos. Una página inusitada de la Tradición Clásica» en Cuadernos de Filología Clásica. Estudios Latinos, 18, pp. 163-216.

GonZÁlez-Rivas FernándeZ, Ana y García Jurado, Francisco, «Death and Love in Poe's and Schwob's Readings of the Classics». CLCweb: Comparative Literature and Culture, 10:4 (2008): http://docs.lib.purdue.edu/clcweb/vol10/iss4/4

GONZÁlEZ-RIVAS FERNÁNDEZ, Ana (2008) El mundo clásico desde la mirada femenina (e-book), Liceus.Com.Portal de Humanidades, E-Excellence, 2008: http://www.liceus.com/bonos/ compra1.asp?idoproducto $=1163$

GONZÁLEZ-RIVAS FERNÁNDEZ, Ana (2006) «Frankenstein; or the Modern Prometheus: una tragedia griega», Minerva: Revista de filología clásica, 19, pp. 309-326.

Obras literarias antiguas. Ediciones y traducciones

Homero (2000) Ilíada, Emilio Crespo Güemes (introducción, traducción y notas), Madrid, Gredos, Biblioteca Clásica de Gredos.

Homero (1963) Ilíada, David B. Monro \& Thomas W. Allen (edición crítica), Tomos 1 y 2, Oxford, Clarendon Press.

Ovidio (1988) Fastos, Bartolomé Segura Ramos (introducción, traducción y notas), Madrid, Gredos, Biblioteca Clásica de Gredos.

Plinio el Joven (1968) Epistulae, R. A. B. Mynors (edición crítica), Oxford, Clarendon Press.

Virgilio (2003) Obras Completas. Edición bilingüe, Aurelio Espinosa Pólit (traducción de Bucólicas, Geórgicas y Eneida); Arturo Soler Ruiz (traducción de Apéndice virgiliano); Pollux Hernúñez (edición, introducción y apéndices; traducción de la Vida de Virgilio), Madrid, Cátedra, Biblioteca Aurea Cátedra.

Obras literarias modernas. Ediciones y traducciones

MATURIN, Charles Robert (1968) Melmoth, the Wanderer, Grant, D. (ed. e introducción), London New York - Toronto, Oxford University Press.

Maturin, Charles Robert (2005), Melmoth, el errabundo, Torres Oliver, F. (traducción), Madrid, Valdemar, Colección Diógenes. 